\title{
ECTOPARASITES OF LOCAL SCAVENGING CHICKENS OF CENTRAL ETHIOPIA
}

\author{
Hagos Ashenafi ${ }^{1}$ and Eshetu Yimer ${ }^{2 *}$ \\ ${ }^{1}$ Faculty of Veterinary Medicine, Addis Ababa University, PO Box 34, Debre Zeit, Ethiopia \\ 2 Ethiopian Health and Nutrition Research Institute, PO Box 181689 \\ Addis Ababa, Ethiopia. E-mail: esyima_n@yahoo.com
}

\begin{abstract}
Study on identification of ectoparasites of local chickens was conducted from October 2000 to April 2001, on 190 chickens raised under traditional management system in central Ethiopia, namely Jeldu, Sebeta and Awash Melka Kontire. The study indicated that 178 (93.7\%) of the examined chickens were infected by diverse species of ectoparasites. Parasitic examination revealed the presence of fourteen species of ectoparasites (fleas, lice, mites and ticks). The prevalence of ectoparasite infection accounted $84.4 \%, 98.4 \%$ and $100 \%$ in the highland, midland and lowland sites, respectively. Statistical analysis of the results revealed a significant difference $(p<0.05)$ between the prevalence rates of ectoparasites in the mid and lowland zones than the highland zone. This indicates that the number of local chickens infested by ectoparasites is highly influenced by agro-ecology. Menopon gallinae 167 $(87.9 \%)$ was the most prevalent ectoparasite species followed by Menacanthus stramineus $136(71.6 \%)$, while Ornithonyssus species $5(2.6 \%)$ was the least identified. Other mange mites identified included Knemidocoptes mutans 37 (19.5\%), Cytoditus nudus 24 (12.6\%), and Epidermoptes bilobatus 7 (3.7\%). This study has shown that ectoparasites are the highly prevalent infection on traditionally managed local chickens in the study area. Further detailed study with particular reference to ectoparasitism and assessment of their impact is recommended.
\end{abstract}

Key words/phrases: Central Ethiopia, ectoparasites, local chickens, prevalence

\section{INTRODUCTION}

Indigenous birds are raised under traditional or 'backyard' conditions without any input and are difficult to monitor. They comprise up to $99 \%$ of the total estimated 56.5 million chickens in Ethiopia, while $1 \%$ are exotic breeds maintained under intensive management system (ILCA, 1993).

Raising poultry has a long tradition in Ethiopia and the production system shows a clear distinction between the traditional subsistence, low input system compared with small and large-scale commercial systems, which use relatively advanced technology (Alemu Sida, 1985).

The backyard (traditional) production system is characterized by minimum inputs from the owners, usually kept in small numbers and on leftovers other than occasional supplements, grain feeds and household wastes. They breed naturally, receive no specific housing and the standard of housing varies greatly. In most areas, the chickens share the same house with their owners at night (Tadelle Desse, 1996).

In Ethiopia, it is apparent that indigenous chickens are more important than modern intensive production system with regard to total numbers and egg and poultry meat production (Alemu Sida, 1985). Rural poultry production represents a significant part of the rural economy as a source of income for smallholder farmers (Tadelle Desse, 1996).

The main constraints to the development of indigenous chicken production in rural Ethiopia include disease, predation, lack of feed, housing,

\footnotetext{
* Author to whom correspondence should be addressed.
} 
poor management and to a lesser extent financial problems (Alemu Sida, 1985; Edward, 1992; Tadelle Desse, 1996). Different poultry diseases have been recorded in Ethiopia, mainly in exotic birds kept under intensive management systems. The major causes of economic loss were Newcastle disease (ND), coccidiosis, salmonellosis, chronic respiratory disease (CRD) and nutritional deficiencies. In addition fowl cholera, fowl pox, fowl typhoid and leukosis have been known to cause severe losses (Alamargot et al., 1985).

In addition to management problems and inadequate feeding, prevalence of disease also reduces the productivity of chickens under traditional management system (Sonaiya, 1990). Of the diseases that reduce productivity of rural poultry, parasitic diseases come first (Alemu Sida, 1985; Tadelle Desse, 1996). Parasites, both internal and external, are common in the tropics where the standard of husbandry is poor yet climatic conditions are favourable for the development of the parasites (Abebe Wosene et al., 1997). Even though, parasitic diseases are among the major causes that decrease productivity of chickens, they are often neglected, as they are rarely lethal. Although poultry diseases are known to cause marked economic loss, few studies have been done on local chickens in this country (Abebe Wosene et al., 1997). The objective of the present study is, therefore, to identify the major ectoparasites of local scavenging chickens in three different selected agro-climatic zones in central Ethiopia.

\section{MATERIALS AND METHODS}

\section{Description of the study areas}

The study was conducted in three selected sites, representing different agro-climatic zones in central Ethiopia. These include Jeldu, Sebeta and Awash-Melka-Kontire. Jeldu is located $125 \mathrm{Kms}$ west of Addis Ababa at an altitude of 2880 metres above sea level (m.a.s.1.). The area is classified as temperate highland or "Dega", with an annual rainfall of about $1650 \mathrm{~mm}$. The mean annual minimum and maximum temperature is $8^{\circ} \mathrm{C}$ and $19^{\circ} \mathrm{C}$, respectively. Sebeta is located $25 \mathrm{Kms}$ southwest of Addis Ababa at an altitude of 2240 m.a.s.l. The area is classified as mid-altitude zone "Wayna-Dega" climatic zone, with an annual rainfall of about $890 \mathrm{~mm}$. The mean annual minimum and maximum temperature is $15^{\circ} \mathrm{C}$ and $21^{\circ} \mathrm{C}$, respectively. Awash-Melka-Kontire is located some $55 \mathrm{kms}$ southwest of Addis Ababa at an altitude of 1509 m.a.s.l. The area is classified as lowland or "Kolla" climatic zone, with an annual rainfall of about $700 \mathrm{~mm}$. The mean annual minimum and maximum temperature is about $18^{\circ} \mathrm{C}$ and $27^{\circ} \mathrm{C}$, respectively (NMSA, 2000).

\section{Animals and management}

A total of 190 local chickens both apparently healthy and clinically sick, including both sexes and different age groups were purchased from local open-air markets in the respective study areas. The poultry management pattern involving local chickens in the study areas was in all cases free-range traditional system. Chickens were then transported to Sebeta, National Animal Health Research Centre (NAHRC), for detailed laboratory and postmortem examination.

\section{Sample Collection and examination procedure}

Following euthanasia, the skin together with the feathers and legs from each chicken was separated from the underlying integument and placed in a blue plastic bag (to prevent the escape of the ectoparasites and to provide a contrasting back ground during collection). The legs and featherless areas of the body with any seborrhea or crustation were scrapped for microscopic examination. The chickens were then eviscerated and the thoracic cavity opened. Aclose visual inspection of the air sacs and lungs was undertaken to examine the presence of air sac mites. The detected external parasites were collected and preserved in $70 \%$ ethanol for eventual identification. The identification of collected external parasites was carried out based on the morphological features described by Soulsby (1982).

\section{Data analysis}

The prevalence rate was the prevalence of the number of positive animals out of the total number 
of animals examined. Difference in prevalence by explanatory variable (study areas) was investigated by the Fisher's exact test (SPSS, 2002). In all cases $\mathrm{P}<0.05$ was considered as statistically significant.

\section{RESULTS}

Out of the total 190 chickens examined from the three study areas, 178 (93.68\%) were found harbouring different types of ectoparasites. The prevalence of ectoparasite infection was 84.4\%, $98.4 \%$ and $100 \%$ for Jeldu, Sebeta and Awash Melka Kontire, respectively (Table 1).

Table 1. Overall prevalence of ectoparasites in local scavenging chickens in central Ethiopia.

\begin{tabular}{lccc}
\hline \multicolumn{1}{c}{ Study area } & $\begin{array}{c}\text { No. } \\
\text { examined }\end{array}$ & $\begin{array}{c}\text { No. } \\
\text { infected }\end{array}$ & $\begin{array}{c}\text { Prevalence } \\
\text { rate }(\%)\end{array}$ \\
\hline Jeldu & 64 & 54 & 84.4 \\
Sebeta & 65 & 63 & 98.4 \\
Awash Melka & & & \\
Kontire & 61 & 61 & 100 \\
\hline Total & 190 & 178 & 93.7 \\
\hline
\end{tabular}

The highest infection prevalence rate $(100 \%)$ was observed in the chickens examined from Awash Melka Kontire, followed by $98.4 \%$ from Sebeta, representing lowland and midland zones, respectively. A lower prevalence rate of $(84.4 \%)$ occurred in Jeldu, which represents highland areas (Table 1). The mid and low land zones showed statistically significant difference $(p<0.05)$ ectoparasite infection prevalence rates than the highland zone.

The ectoparasite fauna of examined local chickens in central Ethiopia was marked by the presence of one flea species (Echidenophaga gallinacea), one tick species (Argas persicus), five species of mites (Cytoditus nudus, Dermanyssus gallinae, Epidermoptes bilobatus, Knemidocoptes mutans, and Ornithonyssus species) and seven species of lice (Cuclotogaster heterographus, Goniodes gigas, Goniodes dissmilis, Goniocotes gallinae, Lipeurus caponis, Menacanthus stramineus, and Menopon gallinae). Argas persicus (4.6\%) and Ornithonyssus species $(3.1 \%)$ occurred only in the midland and low land $(8.2 \%$ and $3.3 \%)$ zones, respectively; while other ectoparasites occurred in different areas with varying degrees of prevalence (Table 2).

Table 2. Prevalence of ectoparasites of local scavenging chickens in central Ethiopia.

\begin{tabular}{|c|c|c|c|c|}
\hline \multirow{2}{*}{ Ectoparasite species } & \multicolumn{4}{|c|}{ Prevalence $\%$} \\
\hline & Jeldu & Sebeta & Awash Melka Kontire & Over all prevalence \\
\hline \multicolumn{5}{|l|}{ FLEA } \\
\hline Echidenophaga gallinacea & 7 (10.9) & $3(4.6)$ & $3(4.9)$ & $13(6.8)$ \\
\hline \multicolumn{5}{|l|}{ TICKS } \\
\hline Argas persicus & 0 & $3(4.6)$ & $5(8.2)$ & $8(4.2)$ \\
\hline \multicolumn{5}{|l|}{ MITES } \\
\hline Cytoditus nudus & $8(12.5)$ & $6(9.2)$ & $10(16.4)$ & $24(12.6)$ \\
\hline Dermanyssus gallinae & $3(4.7)$ & $7(10.8)$ & $5(8.2)$ & $15(7.9)$ \\
\hline Epidermoptes bilobatus & $1(1.6)$ & $3(4.5)$ & $3(4.9)$ & $7(3.7)$ \\
\hline Knemidocoptes mutans & $7(10.9)$ & $11(16.9)$ & $19(31.2)$ & $37(19.5)$ \\
\hline Ornithonyssus species & 0 & $3(3.1)$ & $2(3.3)$ & $5(2.6)$ \\
\hline \multicolumn{5}{|l|}{ LICE } \\
\hline Cuclotogaster heterographus & $3(4.7)$ & $7(10.8)$ & $5(8.2)$ & $15(7.9)$ \\
\hline Goniodes gigas & $12(18.8)$ & $30(46.2)$ & $27(44.3)$ & $69(36.3)$ \\
\hline Goniodes dissmilis & $4(6.3)$ & $20(31.2)$ & $17(27.9)$ & $41(21.6)$ \\
\hline Goniocotes gallinae & $18(28.1)$ & $38(58.5)$ & $25(40.9)$ & $81(42.6)$ \\
\hline Lipeurus caponis & $7(10.9)$ & $22(33.9)$ & $19(31.2)$ & $48(25.3)$ \\
\hline Menacanthus stramineus & $48(75)$ & $48(73.9)$ & $40(65.6)$ & $136(71.6)$ \\
\hline Menopon gallinae & $51(79.7)$ & $56(86.2)$ & $60(98.4)$ & $167(87.9)$ \\
\hline
\end{tabular}


Of all the ectoparasites recovered Menopon gallinae occurred with an overall prevalence rate of 167 (87.9\%). Ornithonyssus species 5 (2.6\%) was the least identified. Knemidocoptes mutans 37 (19.5\%), Cytoditus nudus 24 (12.6\%), and Epidermoptes bilobatus 7 (3.7\%) were the other mange mites recorded during this study. The major ectoparasites identified in all the three study areas were lice and mites, locally known as"Kenken".

\section{DISCUSSION}

The present study revealed the existence and occurrence of various ectoparasites in local chickens in central Ethiopia. The high prevalence of ectoparasitism is associated partly with the husbandry practice in the backyard low input management system as well as to the conducive environmental factors favouring the propagation and life cycle progression of the diverse parasite fauna in the studied sites.

Statistical analysis of the results revealed a significant difference $(p<0.05)$ between the prevalence rates of ectoparasites in the mid and lowland zones than the highland zones. This indicates that the number of local chickens infested by ectoparasites is highly influenced by agroecology. At higher altitudes, colder temperatures and a lower level of infestation are observed. This may be because the extreme low temperatures of the highland areas inhibit the development and survival of the early stages of ectoparasites. However, the warmer temperatures of the mid and lowland areas provide conducive conditions for the survival, propagation and life cycle progression of the diverse parasite fauna. In this study, the infection prevalence of ectoparasites was highest in Awash Melka Kontire (100\%) and least in Jeldu (84.4\%). A higher $100 \%$ ectoparasite prevalence was reported by Gedion Yilma (1991) in another study carried out in the eastern lowlands of Ethiopia (Dire Dawa). This variation may be due to the variation in the climate of the study areas. Awash Melka Kontire is a place with a higher average temperature and lower annual rainfall. This condition may have favoured the development and transmission of the parasites although this might require further investigation.

The ectoparasite with the highest prevalence encountered in this study was Menopon gallinae (87.9\%). However, Gedion Yilma (1991) and Bersabeh Tigabu (1999) reported relatively lower prevalence rates of Menopon gallinae ${ }_{L}$ in Dire Dawa (51.2\%) and Nazareth (41.7\%), Ethiopia.

Menacanthus stramineus $(71.6 \%)$ was the second most prevalent species of ectoparasite encountered. M. stramineus is the most pathogenic species of poultry lice as it causes severe anaemia by puncturing small feathers and feed on blood that oozes out. It is known to cause inflammation of the skin and extensive scab formation (Urquart et al., 1987).

Scaly leg mite, Knemidocoptes mutans, 37 (19.5\%) is a small spherical sarcoptic mite that usually tunnels into the tissue under the scales causing an inflammation with exudate that hardens on the surface and displace the scales resulting in marked keratinisation, responsible for the thickened scaly nature of the feet (Urquart et al., 1987; Philips, 1991). K. mutans was consistently recovered in this study from chicken with scaly legs having a characteristic thickened leg with scaly nature and marked keratinisation.

Air sac (respiratory system) mites of poultry, Cytoditus nudus was found on the lungs and air sacs of local chickens at a prevalence rate of 24 $(12.6 \%)$. Close inspection of the opened cadaver of an affected bird soon after death revealed whitish dots moving slowly over the transparent air sac surfaces. There is considerable conflict among observers as to the damage caused by air sac mites. Some are of the opinion that they are particularly harmless because their presence has been noted in apparently healthy birds. Others state that the mites are responsible for emaciation, peritonitis, pneumonia and obstruction of air passages and predisposing to tuberculosis (Soulsby, 1982).

Skin mite, Epidermoptes bilobatus was reported in $7(3.7 \%)$ of local scavenging chickens in central Ethiopia and noted to cause lesions with severe dermatitis, and formation of thick, brownish scabs.

The stick tight flea, Echidinophaga gallinacea, is a unique among poultry fleas in that the adults 
become sessile parasites and usually remain attached to the skin of head for days or weeks. It causes irritation and blood loss leading to anaemia and death particularly in young birds (Philips, 1991).

Argas persicus and Dermanyssus gallinae were encountered, at a prevalence rate of $8(4.2 \%)$ and 15 $(7.8 \%)$, respectively. However, this does not reflect the true figure, since both parasites live on hosts for a short period of time and usually at night (Urquart et al., 1987). This result is in agreement with previous reports of Gedion Yilma (1991), Abebe Wosene et al. (1997), Bersabeh Tigabu (1999) and Eshetu Yimer et al. (2000) from different parts of Ethiopia. Ticks inhabiting poultry houses of the family Argasidae, soft ticks, Argas persicus causes loss of blood, reduced production and are notorious transmitters of diseases such as Avian Spirochetosis, Aegyptinella pullorum, an erythrocyte invading protozoan of birds, fowl cholera and possibly other diseases (Philips, 1991). Dermanyssus gallinae, northern fowl mites apart from causing intense pruritis and pain, act as vectors of Borrelia anserina (Urquart et al., 1987).

This study showed that local scavenging chickens had multiple ectoparasite infestations up to 14 species per chicken, which is known to adversely affect their health status and contribute to decreased productivity. Owing to the inherent nature of the management of chicken in rural areas, infectious and parasitic diseases are wide spread exerting their confounding effects on productivity. Application of parasite control schemes must thus receive priority attention. Further efforts need to be intensified in envisaging rural poultry management packages, suitable to different agro-production systems that consider better health care, supplementary feed and housing facilities.

\section{REFERENCES}

1. Abebe Wosene, Asfaw Teferi, Genete Bishu, Kassa Bayou and Dorchies, P.H. (1997). Comparative studies of external parasites and gastrointestinal helminths of chickens kept under dif- ferent management system in and around Addis Ababa, Ethiopia. Rev. Med. Vet. 148:497-500.

2. Alamargot, J., Mengistu Alemayehu and Fesseha Gebreab (1985). Poultry diseases in Ethiopia. Rev. Med. Vet. 38(2):130-137.

3. Alemu Sida (1985). The status of poultry research and development in Ethiopia. In: The Status of Livestock, Pasture and Forage Research and Development in Ethiopia. Proceedings of the Institute of Agricultural Research (IAR), Addis Ababa, pp. 62-70.

4. Bersabeh Tigabu (1999). A survey of Ectoparasites and GI helminths of backyard chickens in threeselected agro-climatic zones in central Ethiopia. DVM Thesis, Faculty of Veterinary Medicine, Addis Ababa University, Ethiopia, pp. 61.

5. Edward, H. (1992). Small-scale poultry keeping in Welaita, North Omo region. Farmer's research project (FRP). Technical pamphlet, No. 3. Farm Africa, Addis Ababa, Ethiopia.

6. Eshetu Yimer, Mulualem Enyew, Abera Kebede and Ebrahim Hussien (2000). Mange mites of Poultry in Amhara Regional State. Bull. Anim. Hlth. Prod. Afr. 48(2):119-120.

7. Gedion Yilma (1991). A preliminary survey of Ectoparasites and GI helminthes of local chickens in and around Dire Dawa. DVM Thesis, Faculty of Veterinary Medicine, Addis Ababa University, Ethiopia, pp. 38.

8. ILCA (1993). International Livestock Centre for Africa. Handbook of African Livestock Statistics, pp. 1517.

9. NMSA (2000). National Meteorology Service Agency . Monthly metrological report, Addis Ababa, Ethiopia.

10. Philips, J.R. (1991). Ectoparasites. The Merck Veterinary Manual, $8^{\text {th }}$ ed. National publishing, Inc. Philadelphia, Pennsylvania, pp 1956-1958.

11. SPSS (2002). SPSS for Windows Release No. 11.5.0, Lead Technologies Inc. USA.

12. Sonaiya, E.B. (1990). The context and prospects for development of smallholder rural poultry production in Africa. In: CTA-Seminar Proceedings on Small holder Rural Poultry Production, Vol. 2, pp. 108-141. Thessaloniki, Greece.

13. Soulsby, E.J.L. (1982). Helminths, Arthropods and Protozoa of domesticated Animals, $7^{\text {th }}$ ed. B. Tindall and Casell, pp. 446-456 and 630-645. 
14. Tadelle Desse (1996). Studies on Village poultry production systems in the central highlands of Ethiopia. Msc Thesis, University of Uppsala, Sweden. pp. 72.
15. Urquart, G.M., Armour, J., Duncea, J.L., Dunn, A.M. and Jennigns, F.W. (1987). Veterinary Parasitology. Churchill Living stone Inc, New York, pp. 8-170. 